\title{
Phase I study to assess the safety and tolerability of olaparib in combination with bevacizumab in patients with advanced
}

\section{solid tumours}

\author{
E Dean*,', MR Middleton', T Pwint' ${ }^{2}$, H Swaisland ${ }^{3}$, J Carmichael ${ }^{3,4}$, P Goodege-Kunwar' and M Ranson' \\ 'Clinical Trials Unit, Department of Medical Oncology, The Christie NHS Foundation Trust, The University of Manchester, Wilmslow Road, Manchester \\ M20 4, BX, UK: ${ }^{2}$ University Department of Oncology, Oxford NIHR Biomedical Research Centre, Churchill Hospital, Old Road, Headington, Oxford OX3 \\ 7LJ, UK; ${ }^{3}$ AstraZeneca, Alderley Park, Macclesfield, Cheshire SKIO 4TG, UK
}

\begin{abstract}
BACKGROUND: Olaparib (AZD228I) is a potent oral poly(ADP-ribose) polymerase inhibitor with anti-tumour activity and acceptable toxicity as monotherapy in patients with BRCA-deficient cancers. The vascular endothelial growth factor receptor inhibitor bevacizumab has been incorporated into standard of care with chemotherapy in various tumours. This phase I study established the safety, tolerability and clinical pharmacokinetics of olaparib alone and in combination with bevacizumab.

METHODS: Patients with advanced solid tumours received increasing doses of continuous oral olaparib (I00, 200 and 400 mg b.i.d. capsule formulation) in combination with bevacizumab $\left(10 \mathrm{mg} \mathrm{kg}^{-1}\right.$ intravenous $\left.\mathrm{q} 2 \mathrm{w}\right)$.

RESULTS: In all, 12 patients enrolled and received treatment. The most common adverse events (AEs) related to olaparib were grade I/2 nausea and fatigue. No haematological parameters were reported as AEs. No serious AEs related to olaparib or dose-limiting toxicities (DLTs) were reported. Three patients discontinued due to AEs, two patients discontinued both olaparib and bevacizumab and one patient discontinued olaparib. Five patients received combination treatment for over 6 months. There was no evidence that bevacizumab affected olaparib.

CONCLUSION: The combination of olaparib $400 \mathrm{mg}$ b.i.d. with bevacizumab $10 \mathrm{mg} \mathrm{kg}{ }^{-1} \mathrm{q} 2 \mathrm{w}$ was generally well tolerated with no DLTs. This combination could be considered for future clinical investigation.

British Journal of Cancer (2012) 1 06, 468-474. doi:I0.1038/bjc.2011.555 www.bjcancer.com

Published online 5 January 2012

(C) 2012 Cancer Research UK
\end{abstract}

Keywords: AZD228I; olaparib; bevacizumab; phase I

Poly(ADP-ribose) polymerase (PARP) is a protein that contributes to cell survival after DNA damage (reviewed in Virag and Szabo, 2002). After single- and double-DNA strand breaks, the catalytic domains of PARP-1 and PARP-2 are immediately stimulated to critically initiate and regulate DNA damage repair through the base excision repair (BER) pathway. Loss of PARP activity or PARP inhibition leads to an accumulation of single-strand DNA breaks, which after collapse of DNA replication forks, causes double-strand DNA (dsDNA) breaks and tumour cell death. Pre-clinically, cancer cell sensitivity to radiation and DNA-damaging cytotoxics can be enhanced by PARP inhibition (Virag and Szabo, 2002; Nguewa et al, 2005). Some tumours have a compromised ability to repair dsDNA breaks by homologous recombination, such as those with mutations in the tumour-suppressor genes $B R C A 1$ and BRCA2. Blockade of BER by PARP inhibition results in an accumulation of dsDNA breaks which are lethal in these cells. This has led to the therapeutic concept of synthetic lethality based on combining two non-lethal events which potently synergise for

\footnotetext{
*Correspondence: Dr E Dean; E-mail: emma.dean@christie.nhs.uk

${ }^{4}$ Formerly AstraZeneca.

Received I September 20 I ; revised I4 November 20 I ; accepted 22 November 201 I; published online 5 January 2012
}

lethal effect (Bryant et al, 2005; Farmer et al, 2005; Ashworth, 2008). Germline mutations in the BRCA1 and BRCA2 genes account for $\sim 10 \%$ of ovarian and breast cancer cases (Kwon et al, 2010). However, in addition, some sporadic tumours share a phenotype similar to familial-BRCA cancers due to epigenetic mechanisms of gene inactivation (termed 'BRCAness' phenotype) and it is predicted that these patients could potentially derive clinical benefit from PARP inhibition (Turner et al, 2004).

Olaparib (AZD2281) is a potent oral PARP inhibitor that has exhibited monotherapy activity in tumour cells with defective components of homologous recombination, including cells with the $B R C A 1^{-1-}$ and $B R C A 2^{-1-}$ genotype (Menear et al, 2008; Rottenberg et al, 2008). Pre-clinical studies have shown that olaparib has the potential to selectively target tumour-specific defects by directly inhibiting PARP-1 and PARP-2, either as monotherapy or in combination with cytotoxic agents. A phase I study of olaparib monotherapy in patients with advanced solid tumours demonstrated that olaparib was well-tolerated and established the maximum tolerated dose (MTD) as $400 \mathrm{mg}$ b.i.d. using a capsule formulation (Fong et al, 2009, 2010). Adverse events (AEs) were generally mild and manageable and included nausea and vomiting, fatigue, anorexia, asymptomatic tachycardia, anaemia, neutropaenia and thrombocytopaenia. In this monotherapy study, anti-tumour activity was observed in $B R C A$ 
mutation carriers with $63 \%$ clinical benefit and $47 \%$ radiological response. Subsequently, olaparib was the first oral PARP inhibitor in phase II clinical trials, and monotherapy activity ( $400 \mathrm{mg}$ b.i.d.) was demonstrated with acceptable tolerability in patients with advanced breast or ovarian cancers with $B R C A$-related cancer (Audeh et al, 2010; Tutt et al, 2010). The hypothesis that olaparib, by inhibiting DNA repair, will potentiate DNA damage induced by cytotoxics has been observed in preclinical combination studies. However, four phase I trials of olaparib in combination with topotecan (Samol et al, 2011), dacarbazine (Khan et al, 2011), paclitaxel (Dent et al, 2011) and cisplatin plus gemcitabine (Giaccone et al, 2010) showed dose-limiting bone marrow toxicity that was more pronounced than that seen with chemotherapeutic agents alone; the therapeutic gain from these and other combination approaches (including carboplatin and/or paclitaxel, temozolomide, irinotecan or liposomal doxorubicin) are yet to be established.

Bevacizumab is a humanised recombinant antibody that prevents vascular endothelial growth factor (VEGF) receptor binding, inhibiting angiogenesis and tumour growth. Bevacizumab is licensed in combination with chemotherapy in metastatic colorectal cancer (Hurwitz et al, 2004), renal cell cancer (Escudier et al, 2010) and unresectable advanced non-squamous non-small cell lung cancer (Sandler et al, 2006) (licensed doses $5-10 \mathrm{mg} \mathrm{kg}^{-1} \mathrm{q} 2 \mathrm{w}$ or $\left.7.5-15 \mathrm{mg} \mathrm{kg}^{-1} \mathrm{q} 3 \mathrm{w}\right)$. However, initial tumour responses are invariably followed by disease progression reflecting adaptive resistance (Bergers and Hanahan, 2008). One mechanism of resistance is induction of hypoxia as a response to vessel regression caused by the anti-angiogenic agent, resulting in an increase of DNA damage and genetic instability (Chan and Bristow, 2010). The observation that tumour cells exposed to chronic hypoxia acquire defects in homologous recombination and increased sensitivity to PARP inhibition (Hegan et al, 2010) is an example of 'contextual synthetic lethality' in which hypoxia-induced repair-deficient tumour cells can be targeted by disrupting backup pathways (Chan and Bristow, 2010). Therefore, the premise of combining olaparib and bevacizumab is based on the rationale that direct targeting of PARP by olaparib and indirect sensitisation to olaparib by acquisition of HR defects by bevacizumab will be therapeutically beneficial, and pragmatism as bevacizumab is incorporated into standard-of-care treatments in tumour types that PARP inhibitors have potential to be effective.

The primary objectives of this phase I study were to establish the safety and tolerability of olaparib and bevacizumab combination therapy in patients with advanced solid tumours and to select an appropriate dosing regimen for use in future phase II efficacy studies. Secondary objectives were to compare plasma exposure of olaparib when administered alone and in combination with bevacizumab by assessment of pharmacokinetic (PK) parameters.

\section{METHODS}

\section{Trial design and procedures}

This was a two-centre, open-label phase I study evaluating increasing doses of continuous twice daily oral olaparib (100, 200 and $400 \mathrm{mg}$ b.i.d. capsule formulation) in combination with intravenous bevacizumab at a fixed dose $\left(10 \mathrm{mg} \mathrm{kg}^{-1}\right)$ administered every 14 days. Patients started olaparib monotherapy as run in for 7 days before combination treatment with bevacizumab at cycle 1 . Each treatment cycle lasted 14 days. Bevacizumab was administered $1 \mathrm{~h}$ in advance of olaparib initially over $90 \mathrm{~min}$ and, if well tolerated, for subsequent cycles over $60 \mathrm{~min}$ and then $30 \mathrm{~min}$. All cohorts recruited four patients with planned expansion to six patients in the event of a single dose-limiting toxicity (DLT). To verify dosing compliance and times of olaparib administration, patients were asked to complete a diary card. The end of the study was defined as the date each patient had received a minimum of 6 months treatment.

\section{Eligibility}

Patients aged $\geqslant 18$ years with histologically confirmed metastatic cancer not amenable to curative treatments were eligible for this study. Eastern Cooperative Oncology Group (ECOG) performance status $0-2$, life expectancy of $\geqslant 12$ weeks and adequate bone marrow, liver and kidney function were required. Patients had to have recovered from Common Terminology Criteria for Adverse Events (CTCAEs) grade $\geqslant 2$ toxicities (excluding alopecia) caused by previous therapy and were not permitted to have central nervous system metastases, bleeding diathesis or coagulopathy, poorly controlled hypertension, consecutive $>+1$ proteinuria, recent history of abdominal fistula, gastrointestinal perforation, intra-abdominal abscess, haemorrhage, thrombosis or cardiovascular disease. Written informed consent was obtained from all patients, and this study was approved by an independent ethics committee and conducted in accordance with the Declaration of Helsinki (http://www.ClinicalTrials.gov Identifier NCT00710268).

\section{Toxicity criteria and dose modifications}

Safety assessments included physical examination, haematology and chemistry, electrocardiogram and urinalysis. Toxicities were evaluated at least weekly during the study period and graded using the National Cancer Institute-CTCAE version 3.0. Toxicities were managed by treatment modification or interruption of olaparib until CTCAE grade $\leqslant 1$ or resolution. Treatment could then be restarted at $50 \%$ dose with a maximum of three permissible dose reductions (providing the dose of olaparib was $\geqslant 50 \mathrm{mg}$ b.i.d.). If the $\mathrm{AE}$ failed to resolve during the maximum 28-day interruption period, the patient was withdrawn from the study. No intra-patient dose escalations were permitted. There were no specific dose reductions for the use of bevacizumab, but in the event of toxicity, bevacizumab could be discontinued or temporarily stopped with patients continuing olaparib. A DLT was defined as the following drug-related effects and considered related to olaparib monotherapy during run in or during cycle 1 when in combination with bevacizumab: grade 4 thrombocytopaenia, grade 4 neutropaenia lasting $>5$ days, grade $3 / 4$ febrile neutropaenia, grade $3 / 4$ nausea and/or vomiting despite maximal anti-emetic therapy and other CTCAE grade 3/4 non-haematological toxicities excluding nausea and vomiting.

\section{Pharmacokinetics}

Venous blood was drawn for determination of PK profiles for olaparib when dosed alone and in combination with bevacizumab. Samples were drawn before dosing and then following the morning dose of olaparib at $30 \mathrm{~min}, 1,2,3,4,6,8$ and $12 \mathrm{~h}$ on day-7 and day 1 of cycle 1. Plasma olaparib concentrations were determined by high-performance liquid chromatography with tandem mass spectrometric detection. The PK analysis set only included patients who provided both a full steady-state profile of olaparib when administered alone and in combination with bevacizumab. All plasma concentration-time data were analysed with non-compartmental methods using WinNonlin Version 4.1 Enterprise. Pharsight Corporation, Mountain View, CA, USA.

\section{Statistical methods}

There was no formal statistical analysis of safety and tolerability data. Sample size was dependent on tolerability, safety and PK data acquisition while exposing as few patients as possible to study treatment. 


\section{RESULTS}

\section{Patients and extent of exposure}

In total, 12 patients ( 4 in each treatment group) were enrolled and all received at least one dose of olaparib and bevacizumab (Table 1). All 12 patients had previous chemotherapy, 11 had

Table I Baseline patient demographics and characteristics

\begin{tabular}{|c|c|c|c|c|}
\hline & \multicolumn{4}{|c|}{ Olaparib dose (mg b.i.d.) } \\
\hline & $\begin{array}{c}100 \\
(n=4)\end{array}$ & $\begin{array}{c}200 \\
(n=4)\end{array}$ & $\begin{array}{c}400 \\
(n=4)\end{array}$ & $\begin{array}{l}\text { All patients } \\
\quad(n=12)\end{array}$ \\
\hline \multicolumn{5}{|l|}{ Sex, n (\%) } \\
\hline Male & I & 0 & । & $2(17)$ \\
\hline Female & 3 & 4 & 3 & $10(83)$ \\
\hline Median age (range) & $53(34-65)$ & $5 \mid(22-7 \mid)$ & $53(33-60)$ & $53(22-7 \mid)$ \\
\hline \multicolumn{5}{|l|}{ Race, $n$ (\%) } \\
\hline Caucasian & 3 & 4 & 4 & I| (92) \\
\hline Oriental & I & 0 & 0 & I (8) \\
\hline \multicolumn{5}{|l|}{ ECOG PS at screening, $n(\%)$} \\
\hline 0 & 1 & 3 & 1 & $5(42)$ \\
\hline 1 & 3 & 1 & 3 & $7(58)$ \\
\hline \multicolumn{5}{|l|}{ Previous therapy $n(\%)^{\mathrm{a}}$} \\
\hline Radiotherapy & 2 & I & 2 & $5(42)$ \\
\hline Chemotherapy & 4 & 4 & 4 & $12(100)$ \\
\hline $\begin{array}{l}\text { Immunotherapy/hormone } \\
\text { therapy }\end{array}$ & 0 & 2 & I & $3(25)$ \\
\hline $\begin{array}{l}\text { Other systemic cancer } \\
\text { therapy }\end{array}$ & 2 & 2 & । & $5(42)$ \\
\hline Surgery ${ }^{c}$ & 4 & 3 & 4 & II (92) \\
\hline \multicolumn{5}{|l|}{ Primary tumour site, $n$ (\%) } \\
\hline Colorectal & 2 & 2 & 0 & $4(33)$ \\
\hline Breast & 2 & 0 & I & $3(25)$ \\
\hline Pleura & 0 & 0 & i & I (8) \\
\hline Skin/soft tissue & 0 & I & 0 & $1(8)$ \\
\hline Cervix & 0 & 0 & 1 & | (8) \\
\hline Pseudomyxoma peritonei & 0 & 0 & I & I (8) \\
\hline Upper Gl & 0 & I & 0 & I (8) \\
\hline
\end{tabular}

Abbreviations: $\mathrm{ECOG}=$ Eastem Cooperative Oncology Group performance status;

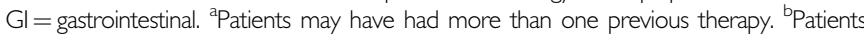
received previous panitumumab (100 mg group), trastuzumab and lapatinib (100 mg group), cetuximab (200 mg group), AGOI4699 (200 mg group) and previous trastuzumab, pertuzumab and lapatinib ( $400 \mathrm{mg}$ group). ${ }^{\top}$ The most common previous surgical procedures were lymphadenectomy $(n=3)$, laparotomy $(n=2)$, proctocolectomy $(n=2)$, splenectomy $(n=2)$, liver operation $(n=2)$ and abdominal operation $(n=2)$. surgery, 5 had radiotherapy, 3 had immunotherapy and 5 had targeted cancer therapies. Patients were heavily pre-treated and 10 had $\geqslant 3$ previous chemotherapy regimens. The most common tumour types were colorectal $(n=4)$ and breast cancer $(n=3)$.

All 12 patients completed at least 5 weeks of treatment with olaparib and at least 2 cycles of bevacizumab. At the end of the study, six patients had discontinued treatment due to disease progression, three discontinued due to toxicity and three were still receiving their initial study treatment (Figure 1). Median total treatment duration was 75 days (range 64-103), 217 days (range $161-229$ ) and 69 days (range 42-194) in the 100, 200 and $400 \mathrm{mg}$ groups, respectively. The greater apparent total treatment duration in the $200 \mathrm{mg}$ group was due to the timing of the data cutoff (i.e., dosing in the $200 \mathrm{mg}$ group started $\sim 1$ month earlier than that in the $400 \mathrm{mg}$ group). However, long-term exposure to treatment ( $>120$ days) was tolerated in all patients in the $200 \mathrm{mg}$ group ( 2 patients received treatment beyond 200 days) and 1 patient in the $400 \mathrm{mg}$ group. Only 1 patient in the $200 \mathrm{mg}$ cohort had a temporary dose interruption of both olaparib and bevacizumab for 21 days due to a serious $\mathrm{AE}$ (SAE) of pathological fracture of the left femur (considered unrelated to study treatment). No other patients had dose modifications in either olaparib or bevacizumab.

\section{Toxicity and safety}

No DLTs were observed at any dose during the study. The 12 patients experienced a total of 135 AEs. The most common AEs, reported in three or more patients, are shown in Table 2 . Gastrointestinal AEs and fatigue were generally mild to moderate (CTCAE grade 1-2), intermittent and manageable on continued treatment, requiring no modification of study treatment. Nine patients reported AEs that the investigator considered to be possibly related to olaparib (Table 2$)$; nausea $(n=5)$ and fatigue $(n=4)$ were the most frequently reported. However, seven of the nine patients had AEs that were also considered by the investigator to be possibly related to bevacizumab treatment: all events of dry mouth $(n=1)$, fatigue $(n=4)$, lethargy $(n=1)$, epistaxis $(n=1)$, one of two events of mucosal inflammation and one of five events of nausea. In addition, five patients had events that were attributable only to bevacizumab, splinter nail haemorrhage, small intestinal obstruction, intestinal perforation, hypertension, dizziness and anastomotic ulcer $(n=1$ each) and epistaxis $(n=2)$.

Six patients had $\geqslant 2$ category changes in urinalysis parameters (three patients each with haematuria or proteinuria), none of

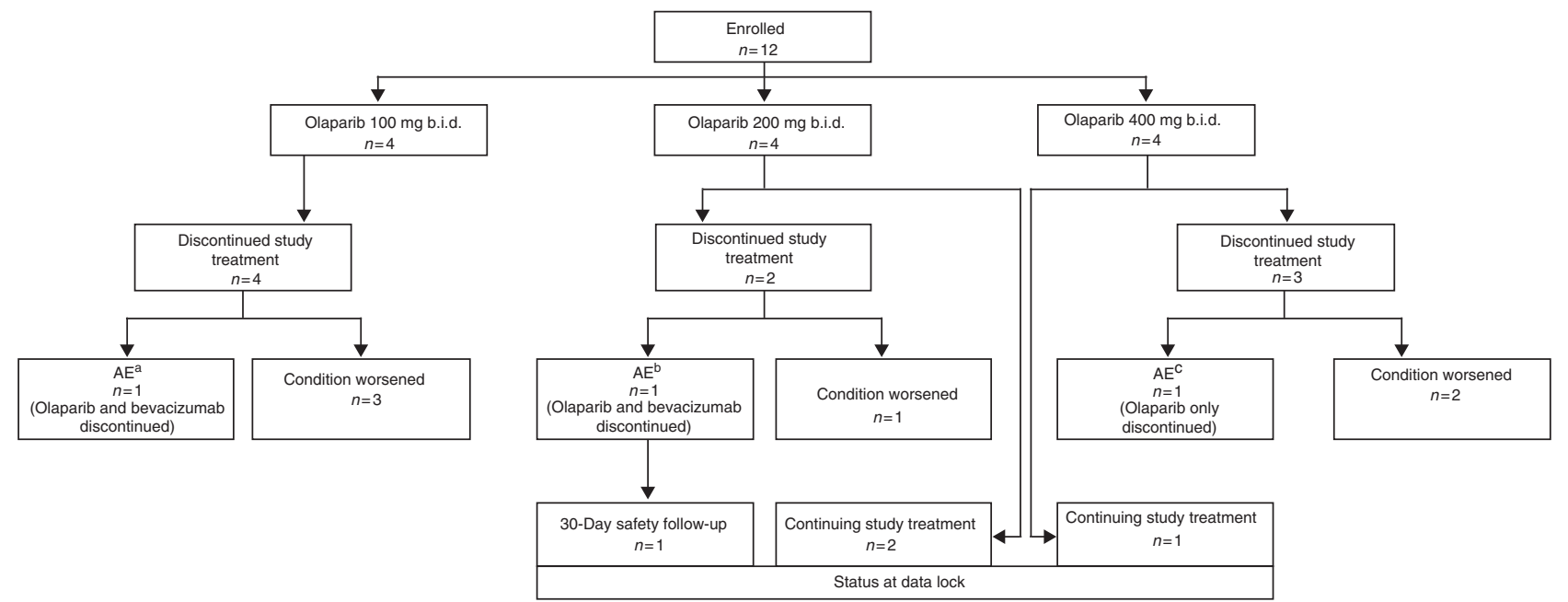

aOlaparib and bevacizumab permanently stopped due to CTCAE grade 4 SAE of small intestinal obstruction with CTCAE grade 3 SAE of intestinal perforation, causally related to bevacizumab: bOlaparib and bevacizumab permanently stopped due to CTCAE grade 3 SAE of metastatic bone pain, causally unrelated to both olaparib and bevacizumab; Colaparib alone permanently discontinued due to CTCAE grade 2 AEs of diarrhea and nausea and CTCAE grade 1 fatigue, considered causally, related to olaparib (bevacizumab had already been permanently discontinued due to investigator decision).

Figure I Disposition of all enrolled patients. 
Table 2 Adverse events, DLTs, serious adverse events

\begin{tabular}{|c|c|c|c|c|}
\hline \multirow[b]{2}{*}{ Number of patients } & \multicolumn{3}{|c|}{$\begin{array}{l}\text { Olaparib (mg b.i.d.) Number } \\
\text { of patients (events) }\end{array}$} & \multirow{2}{*}{$\begin{array}{c}\begin{array}{c}\text { Total } \\
\text { patients }(\%)\end{array} \\
(n=12)\end{array}$} \\
\hline & $100(n=4)$ & $200(n=4)$ & $400(n=4)$ & \\
\hline $\begin{array}{l}\text { Total patients with } \geqslant 1 \mathrm{AE} \\
\text { Adverse events occurring in } \\
\geqslant 3 \text { patients (all causality) }\end{array}$ & $4(17)$ & $4(7 \mathrm{I})$ & $4(47)$ & $12(100)$ \\
\hline Nausea & 0 & 4 & 3 & $7(58)$ \\
\hline Constipation & 0 & 3 & I & $4(33)$ \\
\hline Diarrhoea & 0 & 2 & 2 & $4(33)$ \\
\hline Vomiting & 0 & 3 & 0 & $3(25)$ \\
\hline Fatigue & I & 2 & 3 & $6(50)$ \\
\hline Headache & 1 & 2 & 2 & $5(42)$ \\
\hline Dizziness & 0 & I & 2 & $3(25)$ \\
\hline Epistaxis & 0 & 3 & I & $4(33)$ \\
\hline Oropharyngeal pain & 0 & 3 & 0 & $3(25)$ \\
\hline $\begin{array}{l}\text { Patients with } \geqslant 1 \mathrm{AE} \\
\text { related to olaparib }\end{array}$ & $2(3)$ & $3(5)$ & $4(11)$ & $9(75)$ \\
\hline \multicolumn{5}{|l|}{ AEs related to olaparib ${ }^{\mathrm{a}}$} \\
\hline Nausea & 0 & 2 & 3 & $5(42)$ \\
\hline Fatigue & 0 & 1 & 3 & $4(33)$ \\
\hline Mucosal inflammation & 1 & 0 & I & $2(17)$ \\
\hline Dysgeusia & 1 & 0 & 1 & $2(17)$ \\
\hline Diarrhoea & 0 & 0 & i & ( (8) \\
\hline Dry mouth & 0 & 0 & 1 & । (8) \\
\hline Dyspepsia & 1 & 0 & 0 & I (8) \\
\hline Headache & 0 & 0 & I & ( (8) \\
\hline Lethargy & 0 & I & 0 & । (8) \\
\hline Epistaxis & 0 & I & 0 & I (8) \\
\hline $\begin{array}{l}\text { Patients with AEs of } \\
\text { CTCAE grade } \geqslant 3\end{array}$ & I (3) & I (5) & I (I) & $3(25)$ \\
\hline \multicolumn{5}{|l|}{ AE of CTCAE grade $\geqslant 3$} \\
\hline Dyspnoea & 0 & 0 & I & I (8) \\
\hline $\begin{array}{l}\text { Bone/flank/extremity/ } \\
\text { metastatic pain/ } \\
\text { pathological fracture }\end{array}$ & 0 & I & 0 & I (8) \\
\hline $\begin{array}{l}\text { Small intestinal } \\
\text { obstruction/intestinal } \\
\text { obstruction/intestinal } \\
\text { perforation }\end{array}$ & I & 0 & 0 & । (8) \\
\hline Patients with SAEs & I (3) & I (2) & $2(3)$ & $4(33)$ \\
\hline \multicolumn{5}{|l|}{ SAES } \\
\hline $\begin{array}{l}\text { Pathological fracture/ } \\
\text { metastatic pain }\end{array}$ & 0 & I & 0 & । (8) \\
\hline Subclavian thrombosis & 0 & 0 & 1 & । (8) \\
\hline $\begin{array}{l}\text { Lower respiratory tract } \\
\text { infection }\end{array}$ & 0 & 0 & । & I (8) \\
\hline Pyrexia & 0 & 0 & 1 & । (8) \\
\hline $\begin{array}{l}\text { Small intestinal } \\
\text { obstruction } / \text { intestinal } \\
\text { obstruction/intestinal } \\
\text { perforation }\end{array}$ & । & 0 & 0 & ( (8) \\
\hline
\end{tabular}

Abbreviations: $A E=$ adverse event; $C T C A E=$ Common Terminology Criteria for Adverse Event; $\mathrm{DLT}=$ dose-limiting toxicity; $\mathrm{SAE}=$ serious adverse event. ${ }^{\mathrm{a} C a u s a t i o n}$ assessed by the investigator. ${ }^{b}$ Considered by the investigator to be related to bevacizumab treatment.

which were reported as clinically important. There were no clinically relevant changes, or reported AEs, in haematology/ clinical chemistry parameters after olaparib treatment alone or in combination compared with pre-dose values. Any observed changes were generally mild transient isolated events requiring no study treatment modification. Six patients reported seven bleeding events during the study; one, three and two patients in the 100, 200 and $400 \mathrm{mg}$ groups, respectively. There were four events of epistaxis and one each of haemoptysis, splinter haemorrhage and haematoma. All bleeding events were mild (CTCAE grade 1) and manageable on continued treatment. The international normalised ratio (INR) was normal in all six patients (none were taking anticoagulants).
Three patients experienced nine events of CTCAE grade $\geqslant 3$ (one patient in each dose group; Table 2), none of which were considered by the investigators to be related to olaparib treatment. Four patients experienced a total of eight SAEs (Table 2), none of which were considered to be related to olaparib. In the $100 \mathrm{mg}$ group, a patient had small intestinal obstruction/perforation considered to be related to bevacizumab; a patient in the $200 \mathrm{mg}$ group experienced a pathological fracture of the femur/metastatic pain; one patient in the $400 \mathrm{mg}$ group had a subclavian vein thrombosis and a lower respiratory tract infection; and one patient in the $400 \mathrm{mg}$ group had pyrexia. There were no deaths in the study. Three patients discontinued study treatment due to AEs; two patients discontinued both olaparib and bevacizumab treatment due to SAEs (one patient with metastatic pain unrelated to study treatment and one patient with small intestinal obstruction with perforation considered related to bevacizumab treatment), and one patient discontinued olaparib treatment only due to AEs considered related to olaparib treatment (grade 2 diarrhoea and nausea and grade 1 fatigue; Figure 1).

\section{Pharmacokinetics}

Three patients were excluded from the PK analysis set (two from the $100 \mathrm{mg}$ group and one patient from the $200 \mathrm{mg}$ group) because of blood sampling discrepancies. In addition, for the remaining two patients in the $100 \mathrm{mg}$ group, the time that the second daily dose of olaparib was administered meant that only $\mathrm{C}_{\mathrm{ss}, \max }, \mathrm{t}_{\max }$ and $\mathrm{C}_{\text {ss, max }}$ ratio data could be reported (Table 3). For both the 200 and $400 \mathrm{mg}$ groups, the $\mathrm{Gmean}_{\mathrm{AUC}}$ for olaparib in combination with bevacizumab was similar to that when administered alone (26.6 compared with $25.8 \mu \mathrm{g} \mathrm{h} \mathrm{ml}^{-1}$ for the $200 \mathrm{mg}$ group, and 50.3 compared with $58.1 \mu \mathrm{g} \mathrm{h} \mathrm{ml}^{-1}$ for the $400 \mathrm{mg}$ group), with similar inter-patient variability (CV\%). Similar results were observed for the Gmean $\mathrm{C}_{\mathrm{ss} \text {, max }}$ (Table 3; Figure 2). For the two patients administered $100 \mathrm{mg}$ olaparib who had available data, one patient had a $\mathrm{C}_{\text {ss, max }}$ value in combination with bevacizumab that was within $15 \%$ of that for olaparib alone; the other patient showed a $40 \%$ decrease. The mean ratios of olaparib $\mathrm{AUC}_{\mathrm{ss}}$ and $\mathrm{C}_{\mathrm{ss} \text {, max }}$ (olaparib with bevacizumab to olaparib alone) for both the 200 and $400 \mathrm{mg}$ groups were both near to 1.0 (1.0 and 0.9 for $\mathrm{AUC}_{\mathrm{ss}}$ and 1.1 and 0.9 for $\mathrm{C}_{\mathrm{ss} \text {, max }}$, respectively; Table 3 ). Of the seven assessable patients, four had $\mathrm{AUC}_{\text {ss }}$ values in combination with bevacizumab that were within $10 \%$ of those values for olaparib alone, and three had values within $20 \%$. These results were also reflected in the data for the individual ratios of $\mathrm{C}_{\mathrm{ss} \text { max }}$. Overall, although based on only a limited number of patients, these data suggest that olaparib exposure is unaffected by co-administration of bevacizumab.

\section{DISCUSSION}

The primary objectives of this phase I study were to establish the safety and tolerability of twice daily olaparib when administered in combination with bevacizumab to patients with advanced solid tumours. In addition, this study aimed to select an appropriate dosing regimen of olaparib in combination with bevacizumab for use in future phase II studies. The MTD of olaparib has previously been determined in patients with solid tumours at $400 \mathrm{mg}$ b.i.d. (Fong et al, 2009). In this study, no AEs of CTCAE grade $\geqslant 3$, SAEs or DLTs were observed with olaparib, and the dose level of olaparib $400 \mathrm{mg}$ b.i.d. with bevacizumab $10 \mathrm{mg} \mathrm{kg}^{-1} \mathrm{q} 2 \mathrm{w}$ had an acceptable tolerability profile and could be considered for future clinical studies.

Fatigue, headache and gastrointestinal AEs were most frequently reported in this study, consistent with the safety profile reported in olaparib monotherapy studies. We did not observe myelosuppression as previously published (anaemia $3-17 \%$, thrombocytopaenia 3\%, neutropaenia 2-9\%) (Fong et al, 2009, 2010; Audeh et al, 2010; 
Table 3 Pharmacokinetic parameters of olaparib alone and in combination with bevacizumab

Olaparib dose (mg b.i.d.)

\begin{tabular}{|c|c|c|c|c|c|c|}
\hline PK parameter & $100(n=2)$ & $\begin{array}{c}100+\text { bevacizumab } \\
(n=2)\end{array}$ & $\begin{array}{c}200 \\
(n=3)\end{array}$ & $\begin{array}{c}200+\text { bevacizumab } \\
(n=3)\end{array}$ & $\begin{array}{c}400 \\
(n=4)\end{array}$ & $\begin{array}{c}400+\text { bevacizumab } \\
(n=4)\end{array}$ \\
\hline $\mathrm{C}_{\mathrm{ss}, \min ,} \mu \mathrm{g} \mathrm{ml^{-la }}$ & N/A & NA & $0.5(191.2)$ & $0.6(158.6)$ & $1.6(46.1)$ & $1.3(43.9)$ \\
\hline $\mathrm{A} \cup \mathrm{C}_{\mathrm{ss}}, \mu \mathrm{ghml^{- \textrm {a } }}$ & NA & NA & $25.8(70.0)$ & $26.6(78.1)$ & $58.1(29.4)$ & $50.3(23.1)$ \\
\hline$A \cup C_{s s}$, ratio & NA & NA & NA & $1.0(12.0)$ & NA & $0.9(6.1)$ \\
\hline $\mathrm{C}_{\mathrm{ss}, \max }$ ratio $^{\mathrm{c}, \mathrm{e}}$ & NA & 0.7 & NA & I.I (22.1) & NA & $0.9(12.2)$ \\
\hline
\end{tabular}

Abbreviations: $\mathrm{AUC}_{\mathrm{ss}}=$ area under the plasma concentration-time curve during any dosing interval at steady state; $\mathrm{C}_{\mathrm{ss} \text { max }}=$ maximum plasma (peak) concentration in plasma during dosing interval; $\mathrm{C}_{\mathrm{ss}, \mathrm{min}}=$ minimum plasma (trough) concentration in plasma during dosing interval; $\mathrm{CV}=\mathrm{coefficient}$ of variation; $\mathrm{G}_{\mathrm{mean}}=$ geometric mean; $\mathrm{NA}=$ not assessable; $\mathrm{PK}=$ pharmacokinetics; $\mathrm{t}_{\max }=$ time to reach peak or maximum concentration of maximum response after drug administration. ${ }^{\mathrm{a}} \mathrm{Gmean}$ (CV\%). ${ }^{\mathrm{b}}$ Median (range). ${ }^{\mathrm{C}}$ Mean $(\mathrm{CV} \%)$. ${ }^{\mathrm{d}}$ Ratio of $\mathrm{AUC}_{\mathrm{ss}}=\mathrm{AUC}_{\mathrm{ss}}$ for olaparib in combination with bevacizumab to $\mathrm{AUC}_{\mathrm{ss}}$ for olaparib alone. ${ }^{\mathrm{e}}$ Ratio of $\mathrm{C}_{\mathrm{ss}, \mathrm{max}}=\mathrm{C}_{\mathrm{ss}, \mathrm{max}}$ for olaparib in combination with bevacizumab to $\mathrm{C}_{\mathrm{ss}, \max }$ for olaparib alone.
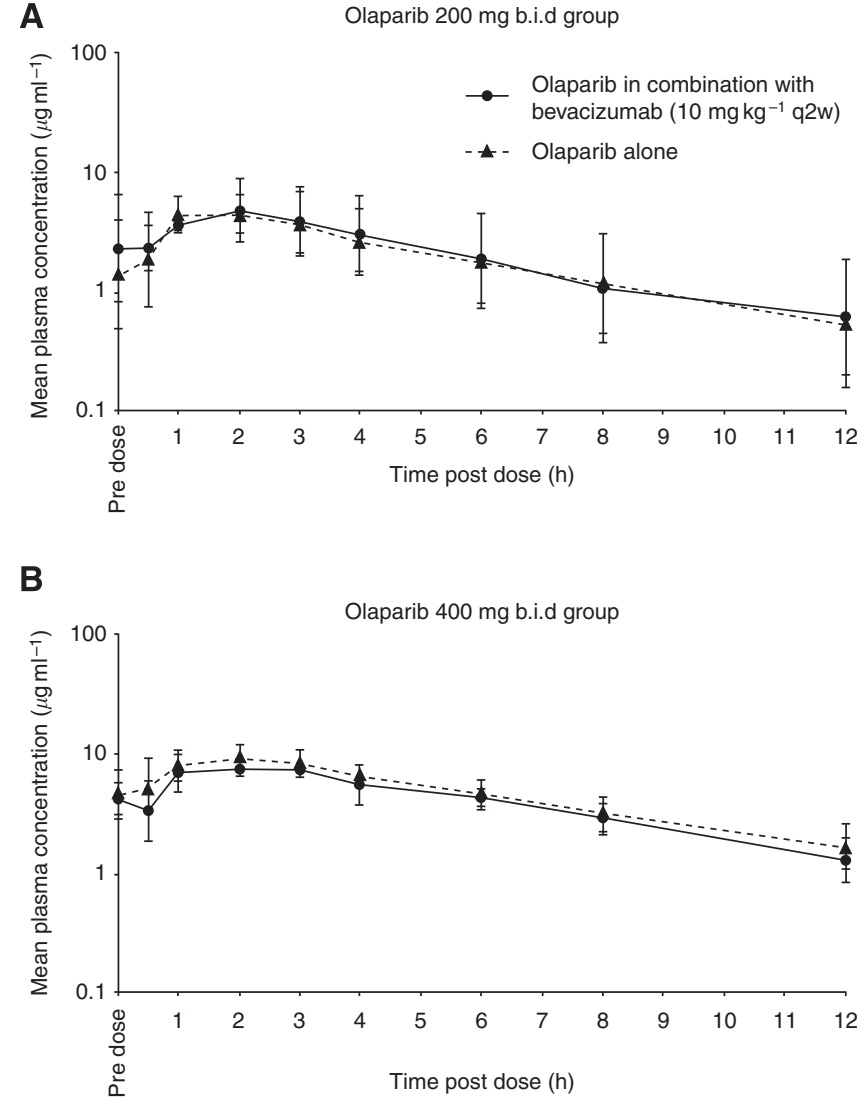

Figure 2 Geometric mean ( \pm s.d.) plasma concentrations of $(\mathbf{A})$ olaparib $200 \mathrm{mg}$ b.i.d. and (B) olaparib $400 \mathrm{mg}$ b.i.d. alone and in combination with bevacizumab (PK analysis set).

Tutt et al, 2010). In monotherapy studies, grade $3 / 4$ haematological toxicities were generally manageable on continued treatment. However, in combination with chemotherapeutics, higher rates of haematological AEs were observed (23-42\% neutropaenia (Giaccone et al, 2010; Samol et al, 2011; Khan et al, 2011)), which were refractory to secondary prophylaxis with G-CSF (Dent et al, 2011). This suggests that olaparib potentiates cytotoxic-induced myelosuppresion and that overlapping toxicities may restrict future development of some olaparib-cytotoxic combinations. Most of the AEs observed in this study were CTCAE grade $1 / 2$ and no dose reductions were required. Three patients discontinued study treatment due to AEs only, one of which was considered related to olaparib, no further unexpected safety issues were observed with this treatment regimen. Four patients received combination treatment for $>6$ months but only one patient in the $400 \mathrm{mg}$ group received treatment for $>3$ months. This suggests long-term tolerability to chronic dosing, but requires further assessment at the recommended phase two dose.

Fatigue and epistaxis were the most frequently reported AEs attributed to bevacizumab. Other observed AEs such as headache, hypertension, dizziness and proteinuria have also been associated with bevacizumab (Genetech, 2011). Mucocutaneous haemorrhage such as epistaxis was observed in four patients and, as in this study, is usually manageable. One patient (100 mg group) with a rectal tumour developed small bowel obstruction on day 104, which subsequently perforated necessitating a laparotomy and segmental resection of the small bowel with end-to-end anastomosis. This SAE was considered possibly related to bevacizumab treatment, which has an incidence of gastrointestinal perforation of $0.3-2.4 \%$ (Genetech, 2011). The patient was discontinued from the study and all events resolved post-operatively.

Olaparib is eliminated in humans through the urinary route and faeces, with excretion as a combination of parent compound and metabolites. Metabolism is extensive and, from in vitro data, mainly mediated by CYP3A4 (AstraZeneca data on file). The metabolism and elimination of bevacizumab are similar to endogenous IgG, that is, primarily through proteolytic catabolism (Agency, 2011). Although patient numbers are small, as expected based on the known clearance mechanisms for olaparib and bevacizumab, a PK interaction was not observed.

The toxicities of olaparib and bevacizumab were predictable, non-overlapping and the majority were generally manageable with continued dosing. A recent phase I/II trial of olaparib in combination with the VEGF and c-kit inhibitor, cediranib, in patients with recurrent ovarian or metastatic triple-negative breast cancer (but unknown BRCA status) demonstrated haematological DLTs (grade 4 neutropaenia and thrombocytopaenia) and anticipated class toxicities (grade 3/4 neutropaenia, hypertension, fatigue, anorexia, nausea and asymptomatic pulmonary embolism) with an unconfirmed response rate of $56 \%$ in ovarian cancer patients (Liu et al, 2011). Our study was not designed to assess tumour response, but efficacy of olaparib in combination with VEGF receptor inhibitors alone will need to be demonstrated. One challenge will be identifying a patient population likely to derive benefit, with rational selection based on tumours expressing a 'mutator' phenotype due to the acquisition of repair-deficient cancer cells from an unfavourable tumour microenvironment. One patient population that could benefit from this combination treatment are patients with platinum-sensitive recurrent ovarian cancer; recent studies of olaparib (Ledermann et al, 2011) and bevacizumab (Aghajanian et al, 2011) monotherapy have both 
demonstrated a significant improvement in progression-free survival. However, although patients who were of BRCA1 or BRCA2 mutations did not seem to have an increased risk of adverse effects in the phase I monotherapy trial (Fong et al, 2009), it is plausible that this combination in women with advanced ovarian cancer may yield a higher toxicity profile due to differing disease distribution. Future trials will also need to address how best to integrate olaparib with existing regimens; should olaparib be added to maintenance bevacizumab after first-line chemotherapy or at the emergence of bevacizumab resistance? What is the required duration of olaparib therapy? At present, the olaparib clinical program is focused on identifying sensitive patient subgroups such as BRCA-related cancer, to enrich and maximise clinical benefit from this interesting new compound.

In conclusion, olaparib $400 \mathrm{mg}$ b.i.d. in capsule formulation combined with bevacizumab $10 \mathrm{mg} \mathrm{kg}^{-1} \mathrm{q} 2 \mathrm{w}$ appeared to be a tolerable regimen with no reported DLTs in patients with advanced solid tumours. Future phase II clinical trials of olaparib in combination with bevacizumab, in particular in patients with ovarian cancer, should be considered to assess clinical efficacy and further evaluate the safety and tolerability of this combination.

\section{ACKNOWLEDGEMENTS}

James Carmichael is an ex-employee of AstraZeneca. Mark $\mathrm{R}$ Middleton is supported by the Oxford Experimental Cancer Medicine Centre. We thank the study statistician Mark Wickens, formerly of AstraZeneca, for providing assistance with the data summaries for the clinical study report. We also thank Claire Routley, $\mathrm{PhD}$, from Mudskipper Bioscience, for editing assistance funded by AstraZeneca. This study was sponsored by AstraZeneca.

\section{Disclaimer}

Mark R Middleton has received honoraria and research funding from AstraZeneca and Roche. Jim Carmichael is an ex-employer of AstraZeneca and holds stock in AstraZeneca. Helen Swaisland is employee of and holds stock in AstraZeneca.

\section{REFERENCES}

Agency EM (2011) Avastin: European Public Assessment Report EMEA/H/ $\mathrm{C} / 000582-\mathrm{II} / 0040$

Aghajanian C, Finkler NJ, Rutherford T, Teneriello MG, Yi J, Parmar H, Nycum LR, Sovak MA (2011) OCEANS: a randomized, double-blinded, placebo-controlled phase III trial of chemotherapy with or without bevacizumab (BEV) in patients with platinum-sensitive recurrent epithelial ovarian (EOC), primary peritoneal (PPC), or fallopian tube cancer (FTC). J Clin Oncol 29(suppl): abst LBA5007

Ashworth A (2008) A synthetic lethal therapeutic approach: poly(ADP) ribose polymerase inhibitors for the treatment of cancers deficient in DNA double-strand break repair. J Clin Oncol 26: $3785-3790$

Audeh MW, Carmichael J, Penson RT, Friedlander M, Powell B, BellMcGuinn KM, Scott C, Weitzel JN, Oaknin A, Loman N, Lu K, Schmutzler RK, Matulonis U, Wickens M, Tutt A (2010) Oral poly(ADP-ribose) polymerase inhibitor olaparib in patients with $B R C A 1$ or BRCA2 mutations and recurrent ovarian cancer: a proof-of-concept trial. Lancet 376: $245-251$

Bergers G, Hanahan D (2008) Modes of resistance to anti-angiogenic therapy. Nat Rev Cancer 8: 592-603

Bryant HE, Schultz N, Thomas HD, Parker KM, Flower D, Lopez E, Kyle S, Meuth M, Curtin NJ, Helleday T (2005) Specific killing of BRCA2deficient tumours with inhibitors of poly(ADP-ribose) polymerase. Nature 434: $913-917$

Chan N, Bristow RG (2010) Contextual" synthetic lethality and/or loss of heterozygosity: tumor hypoxia and modification of DNA repair. Clin Cancer Res 16: $4553-4560$

Dent RA, Lindeman GJ, Clemons M, Wildiers H, Chan A, McCarthy NJ, Singer CF, Lowe ES, Kemsley K, Carmichael J (2011) Safety and efficacy of the oral PARP inhibitor olaparib (AZD2281) in combination with paclitaxel for the first- or second-line treatment of patients with metastatic triple-negative breast cancer: results from the safety cohort of a phase I/II multicenter trial. J Clin Oncol 28(15S): abst 1018

Escudier B, Bellmunt J, Negrier S, Bajetta E, Melichar B, Bracarda S, Ravaud A, Golding S, Jethwa S, Sneller V (2010) Phase III trial of bevacizumab plus interferon alfa-2a in patients with metastatic renal cell carcinoma (AVOREN): final analysis of overall survival. J Clin Oncol 28: $2144-2150$

Farmer H, McCabe N, Lord CJ, Tutt AN, Johnson DA, Richardson TB, Santarosa M, Dillon KJ, Hickson I, Knights C, Martin NM, Jackson SP, Smith GC, Ashworth A (2005) Targeting the DNA repair defect in BRCA mutant cells as a therapeutic strategy. Nature 434: $917-921$

Fong PC, Boss DS, Yap TA, Tutt A, Wu P, Mergui-Roelvink M, Mortimer P, Swaisland H, Lau A, O'Connor MJ, Ashworth A, Carmichael J, Kaye SB, Schellens JHM, de Bono JS (2009) Inhibition of poly(ADP-ribose) polymerase in tumors from BRCA mutation carriers. N Engl J Med 361: 123-134

Fong PC, Yap TA, Boss DS, Carden CP, Mergui-Roelvink M, Gourley C, De Greve J, Lubinski J, Shanley S, Messiou C, A'Hern R, Tutt A, Ashworth A, Stone J, Carmichael J, Schellens JHM, de Bono JS, Kaye SB (2010)
Poly(ADP)-ribose polymerase inhibition: frequent durable responses in BRCA carrier ovarian cancer correlating with platinum-free interval. $J$ Clin Oncol 28: $2512-2519$

Genetech (2011) Avastin prescribing information. http://www.gene.com/ gene/products/information/pdf/avastin-prescribing.pdf

Giaccone G, Rajan A, Kelly RJ, Gutierrez M, Kummar S, Yancey M, Ji JJ, Zhang Y, Parchment RE, Doroshow JH (2010) A phase I combination study of olaparib (AZD2281; KU-0059436) and cisplatin (C) plus gemcitabine (G) in adults with solid tumors. J Clin Oncol 28(15S): abst 3027

Hegan DC, Lu Y, Stachelek GC, Crosby ME, Bindra RS, Glazer PM (2010) Inhibition of poly(ADP-ribose) polymerase down-regulates BRCA1 and RAD51 in a pathway mediated by E2F4 and p130. Proc Natl Acad Sci USA 107: $2201-2206$

Hurwitz H, Fehrenbacher L, Novotny W, Cartwright T, Hainsworth J, Heim W, Berlin J, Baron A, Griffing S, Holmgren E, Ferrara N, Fyfe G, Rogers B, Ross R, Kabbinavar F (2004) Bevacizumab plus irinotecan, fluorouracil, and leucovorin for metastatic colorectal cancer. $N$ Engl J Med 350: 2335-2342

Khan OA, Gore M, Lorigan P, Stone J, greystoke A, Burke W, Carmichael J, Watson AJ, McGown G, Thorncroft M, Margison GP, Califano R, Larkin J, Wellman S, Middleton MR (2011) A phase I study of the safety and tolerability of olaparib (AZD2281, KU0059436) and dacarbazine in patients with advanced solid tumours. Br J Cancer 104: 750-755

Kwon JS, Daniels MS, Sun CC, Lu KH (2010) Preventing future cancers by testing women with ovarian cancer for BRCA mutations. J Clin Oncol 28: $675-682$

Ledermann J, Harter P, Gourley C, Friedlander M, Vergote I, Rustin G, Scott C, Meier W, Shapira Frommer R, Safra T, Matei D, MacPherson E, Watkins C, Carmichael J, Matulonis U (2011) Phase II randomized placebo-controlled study of olaparib (AZD2281) in patients with platinum-sensitive relapsed serous ovarian cancer (PSR SOC). J Clin Oncol 29(Suppl): abst 5003

Liu J, Fleming GF, Tolaney SM, Birrer MJ, Penson RT, Berlin ST, Whalen C, Tyburski K, Matijjevich K, Kasparian E, Roche M, Lee H, Winer EP, Ivy SP, Matulonis U (2011) A phase I trial of the PARP inhibitor olaparib (AZD2281) in combination with the antiangiogenic cediranib (AZD2171) in recurrent ovarian or triple-negative breast cancer. J Clin Oncol 29(Suppl): Abst 5028

Menear KA, Adcock C, Boulter R, Cockcroft XL, Copsey L, Cranston A, Dillon KJ, Drzewiecki J, Garman S, Gomez S, Javaid H, Kerrigan F, Knights C, Lau A, Loh Jr VM, Matthews IT, Moore S, O'Connor MJ, Smith GC, Martin NM (2008) 4-[3-(4-Cyclopropanecarbonylpiperazine1-carbonyl)-4-fluorobenzyl]-2H-phthalazin- 1-one: a novel bioavailable inhibitor of poly(ADP-ribose) polymerase-1. J Med Chem 51: 6581-6591

Nguewa PA, Fuertes MA, Valladares B, Alonso C, Perez JM (2005) Poly(ADP-ribose) polymerases: homology, structural domains and functions. Novel therapeutical applications. Prog Biophys Mol Biol 88: 143-172 
Rottenberg S, Jaspers JE, Kersbergen A, van der Burg E, Nygren AO, Zander SA, Derksen PW, de Bruin M, Zevenhoven J, Lau A, Boulter R, Cranston A, O'Connor MJ, Martin NM, Borst P, Jonkers J (2008) High sensitivity of BRCA1-deficient mammary tumors to the PARP inhibitor AZD2281 alone and in combination with platinum drugs. Proc Natl Acad Sci USA 105: $17079-17084$

Samol J, Ranson M, Scott E, MacPherson E, Carmichael J, Thomas A, Cassidy J (2011) Safety and tolerability of the poly(ADP-ribose) polymerase (PARP) inhibitor, olaparib (AZD2281) in combination with topotecan for the treatment of patients with advanced solid tumors: a phase I study. Invest New Drugs; doi:10.1007/s10637-011-9682-9; e-pub ahead of print 18 May 2011
Sandler A, Gray R, Perry MC, Brahmer J, Schiller JH, Dowlati A, Lilenbaum R, Johnson DH (2006) Paclitaxel-carboplatin alone or with bevacizumab for non-small-cell lung cancer. $N$ Engl J Med 355: $2542-2550$

Turner N, Tutt A, Ashworth A (2004) Hallmarks of 'BRCAness' in sporadic cancers. Nat Rev Cancer 4: 814-819

Tutt A, Robson M, Garber JE, Domchek SM, Audeh MW, Weitzel JN, Friedlander M, Arun B, Loman N, Schmutzler RK, Wardley A, Mitchell G, Earl H, Wickens M, Carmichael J (2010) Oral poly(ADP-ribose) polymerase inhibitor olaparib in patients with BRCA1 or BRCA2 mutations and advanced breast cancer: a proof-of-concept trial. Lancet 376: $235-244$

Virag L, Szabo C (2002) The therapeutic potential of poly(ADP-ribose) polymerase inhibitors. Pharmacol Rev 54: 375-429

This work is published under the standard license to publish agreement. After 12 months the work will become freely available and the license terms will switch to a Creative Commons Attribution-NonCommercial-Share Alike 3.0 Unported License. 